\title{
Health-related quality of life and sense of coherence among Polish immigrants in Germany and indigenous Poles
}

\section{Eva Morawa and Yesim Erim}

Friedrich-Alexander University Erlangen-Nürnberg

\begin{abstract}
Immigrants are faced with several impediments in the host country that may affect their quality of life (QoL), but little is known about the impact of these stressors as well as about the protective role of sense of coherence (SoC) in the context of Polish immigration to Germany. Health Related QoL (Short Form Health Survey SF-36) and SoC (Sense of Coherence Scale SOC-29) were assessed in a total sample consisting of 5 I I participants aged between 18 and 84 years (260 Polish immigrants in Germany and 25 I indigenous Poles). Polish immigrants reported a significantly lower mental and physical health-related QoL than the German norm population, but they were comparable to native Poles. This result remained the same when the model was adjusted for age but physical health status was better for immigrants compared with indigenous Poles. Both groups scored significantly lower for SoC than Germans, but did not differ from each other. The main differences concerning the examined variables were with respect to the German norm population and are putatively shaped by culture.
\end{abstract}

\section{Keywords}

Germany, immigrants, mental health, quality of life, sense of coherence

\section{Introduction}

In Germany, almost one fifth of the population are people with an immigration background (Statistisches Bundesamt, 2011a); according to the Embassy of the Republic of Poland in Berlin (Botschaft der Republik Polen in Berlin, n.d.), approximately two million immigrants are of Polish origin (including the first and second generation as well as the resettlers, see following lines) and constitute

\section{Corresponding author:}

Eva Morawa, Psychosomatische und Psychotherapeutische Abteilung, Schwabachanlage 6, 91054 Erlangen, Germany.

Email: eva.morawa@uk-erlangen.de 
therefore one of the three largest immigration groups in German society today, the other two being of Turkish and Russian origin. Polish immigrants present a heterogeneous group with a high percentage of ethnic German resettlers who have an official status as German citizens. After World War II, as a result of the realignment of Poland's borders westwards, German refugees from the former German territories (until 1945: Silesia, East Prussia, and Pomerania) fled or were deported to Germany. In the fifties and sixties of the last century, approximately 500,000 ethnic Germans were resettled in Germany, between 1980 and 1992, this number increased drastically to 800,000 (Info-Dienst Deutsche Aussiedler, 2003). Based on Article 116 of the German Constitution, the ethnic German repatriates were issued German passports. To be recognized as a resettler, two criteria were crucial: German ethnicity and the imminent pressure to immigrate because of discrimination against those persons of German origin. However, the immigration of resettlers from the communist Poland to West Germany must also be seen in the context of the cold war, as a decision for democracy and economic stability. The resettlers enjoyed a privileged status among the immigrants receiving widespread benefits including access to German citizenship, language training, job retraining, welfare payments, etcetera (Dietz, 2008). Whereas the repatriates of the fifties and sixties underwent a "German" socialization, this was not the case for most of the repatriates of the eighties; most of the latter did not speak German and were of a different sociocultural background at the time of their arrival, their repatriation essentially being motivated by the difficult economic and political conditions in Poland (Pallaske, 2002). Whereas formally they were German, many felt like strangers; further stress factors for these immigrants were job- and language-related: Because the lack of language skills and the nonrecognition of Polish vocational degrees, these immigrants were confronted with a loss of social status (Morawa, 2009). In the nineties, a significant decrease in immigration from Poland could be observed because of the restrictions imposed on being recognized as a repatriate. Since that time, mainly seasonal workers with a temporary legal work permit can be registered (Pallaske, 2002).

\section{Findings on mental health of immigrants}

Immigrants in the process of migration and integration into a host country are exposed to multiple challenges and losses; the multiple psychosocial stressors that arise may have an influence on mental health. Most studies on mental health in immigrants demonstrate higher mental distress in the immigrant than in the indigenous population (Bermejo, Mayninger, Kriston, \& Härter, 2010); however, contrary results have also been reported (Glaesmer et al., 2009); these divergent results are not only due to methodological differences or limitations of the studies (Kirkcaldy, Wittig, Furnham, Merbach, \& Siefen, 2006), but also reflect differences in the country of origin and destination, that is, immigrants from a similarly developed country as the host country tend not to differ significantly in health rates compared to the indigenous population (Bischoff \& Wanner, 2008). The differences 
are not only influenced by migration-specific difficulties, but may also be due to social disadvantages arising from the lower socioeconomic status of many immigrants (Lindström, Sundquist, \& Östergren, 2001; Wiking, Johansson, \& Sundquist, 2004).

\section{Health-related quality of life (HRQoL)}

Although assessment of quality of life (QoL) has increased in health research in recent decades, there is no universally accepted definition and a variety of instruments measure different aspects of this variable (Eriksson \& Lindström, 2007). The present study uses a concept of health-related quality of life (HRQoL) which includes health and well-being as well as the functional status in the physical, psychological, and social area (Bullinger, 1994); we used the Short Form Health Survey (SF-36) to measure HRQoL (Gandek et al., 1998).

A comparative study on subjective QoL conducted with elderly Poles and Germans, found a more positive assessment in the German sample (Zych \& Bartel, 1988). Several studies of HRQoL demonstrated worse health status for Polish immigrants compared to the indigenous population (Lindström et al., 2001; Wiking et al., 2004; Wittig, Lindert, Merbach, \& Brähler, 2008). Many of these studies have been conducted in Sweden. For example, a study in Sweden on the health and well-being of older immigrant groups (Eastern and Western Europeans, Nordic immigrants, Mediterraneans and non-Europeans) compared to the native Swedish population demonstrated a poorer subjective health for the immigrants, non-Nordic immigrants (including Polish immigrants) reporting significantly lower mean scores in all SF-36 health domains than the Swedes (Silveira, Skoog, Sundh, Allebeck, \& Stehen, 2002). The reasons for immigration and legal conditions of Polish immigrants in Germany and in Sweden differ. For example, ethnic German resettlers in Germany enjoy a privileged position with German citizenship, support such as language courses and occupational retraining, pension payment, supportive programs for adolescents regarding school, occupational, and social integration (Dietz, 2008). These differences make a study of Polish immigrants in Germany of particular interest.

\section{Sense of coherence (SoC) and health-related quality of life}

SoC is the central construct of Antonovsky's theory of salutogenesis (Antonovsky, 1987) defined as “a person's view of life and capacity to respond to stressful situations" (Lindström \& Eriksson, 2005), allowing them to see the world as comprehensible, manageable, and meaningful. Empirical evidence suggests a strong association between perceived health, especially mental health, and SoC. In general, individuals with a high SoC report better health status. The protective function of high SoC level has been found regardless of sex, age, nationality, ethnicity, and study design (Eriksson \& Lindström, 2006). A review of SoC and its association with QoL including 458 publications and 13 doctoral theses between 
1992 and 2003 documented the positive effect of SoC on QoL (Eriksson \& Lindström, 2007). Studies on children, adults, and families have found correlations ranging from $r=.17$ (among patients with angina pectoris) to 0.77 (among patients with high-risk psychiatric problems). Larger correlations between SoC and QoL have been observed in studies measuring QoL with specific rather than generic instruments and in studies concerning mental health.

\section{Objectives}

The aims of the present study were (a) to compare the effects of migration on HRQoL by comparing HRQoL in Polish immigrants and indigenous Poles with that of the general German population and (b) to examine the association between HRQoL and SoC as a potential protective factor for migrants.

\section{Methods}

\section{Sample}

Between August 2009 and October 2010 probands were recruited in Upper Silesia (Poland) and the Ruhr area (West Germany) according to the "snowball" method, as well as among students of the Silesian University in Poland and students of Polish migration background at the Ruhr University Bochum in Germany. Questionnaires were also distributed in centres in Germany, where a Polish community had been established, for example, after Polish-language mass in religious and cultural groups in Polish churches as well as in nonreligious places promoting Polish culture.

Inclusion criteria for the study were as follows: for all participants: age of consent (18 years) as well as agreement to participate in the study; for the probands in Upper Silesia: Polish citizenship; for the Polish immigrants in Germany adequate knowledge of the Polish language and the status of Polish immigrant according to the definition applied in epidemiological research in Germany (Schenk et al., 2006); that is, having immigrated themselves or at least one of their parents. Therefore, immigrants both from the first and second generation as well as resettlers were included in the study regardless of German citizenship. The inclusion of the second generation was motivated by the argument that persons who belong to the second generation can differ from the indigenous population concerning their social and legal situation as well as their health status although they have not immigrated themselves (Schenk et al., 2006). A majority of the Polish immigrants living in Germany are formally German citizens and thus rank as Germans in statistics; a random sample would, therefore, not include them whereas data collection within the Polish community made it possible to recruit both immigrants of Polish origin with German citizenship as well as immigrants with Polish citizenship. Despite the selected sample, the immigrant collective is representative for the Polish immigrant population living in Germany according to age, marital and employment status, and mean age at arrival in Germany. Beyond this, the sample included much 
diversity, with about 70 professions, different age groups, and social classes from several cities of the Ruhr area.

In Poland, of 309 questionnaires distributed, 255 were returned (response rate: $82.5 \%$ ) while in Germany 264 of $469(56.3 \%)$ were returned for an overall response rate of $69.4 \%$. Four participants were excluded in each of the samples, based on exclusion criteria or inadequate completion of questionnaire. In total, the sample consisted of 511 respondents: 251 from Upper Silesia and 260 from the Ruhr area (only five belonging to the second generation of immigrants). The main sociodemographic characteristics of the samples are presented in Table 1.

Table I. Sociodemographic, socioeconomic and immigrant-specific characteristics.

\begin{tabular}{|c|c|c|c|c|c|c|}
\hline & $\begin{array}{l}\text { Total sample } \\
N=5 \text { II n (\%) }\end{array}$ & $\begin{array}{l}\text { Polish } \\
\text { immigrants } \\
N=260 n(\%)\end{array}$ & $\begin{array}{l}\text { Indigenous } \\
\text { Poles } \\
N=25 \text { I n (\%) }\end{array}$ & $\mathrm{p}$-value & $\begin{array}{l}t \text {-test/ } \\
\chi^{2} \text {-test } \\
\text { values }\end{array}$ & $d f$ \\
\hline \multicolumn{7}{|l|}{ Age } \\
\hline Mean & 38.98 & 42.48 & 35.4 & $<.00 \mathrm{I}^{\mathrm{a}}$ & $5.14 \mid$ & 487.659 \\
\hline$S D^{*}$ & 15.88 & 14.13 & 16.78 & & & \\
\hline Range & $18-84$ & $18-84$ & $18-83$ & & & \\
\hline \multicolumn{7}{|l|}{ Age group } \\
\hline$\leq 40$ years & $299(58.5)$ & $123(47.3)$ & $176(70.1)$ & $<.00 \mathrm{I}^{\mathrm{b}}$ & 31.572 & 2 \\
\hline $4 I-60$ years & $162(31.7)$ & III (42.7) & 51 (20.3) & & & \\
\hline$>60$ years & $47(9.2)$ & $23(8.8)$ & $24(9.6)$ & & & \\
\hline No data & $3(0.6)$ & $3(1.2)$ & - & & & \\
\hline \multicolumn{7}{|l|}{ Gender } \\
\hline Female & $349(68.3)$ & $169(65.0)$ & I80 (7I.7) & $n s^{\mathrm{b}}$ & 2.658 & I \\
\hline Male & 162 (3I.7) & $91(35.0)$ & 7I (28.3) & & & \\
\hline \multicolumn{7}{|l|}{ Marital status } \\
\hline Married & $262(5 \mid .3)$ & I53 (58.8) & $109(43.4)$ & $<.00 \mathrm{I}^{\mathrm{b}}$ & 26.047 & 2 \\
\hline Single & 198 (38.7) & $73(28.1)$ & $125(49.8)$ & & & \\
\hline $\begin{array}{l}\text { Divorced/ } \\
\text { widowed }\end{array}$ & $50(9.8)$ & $33(12.7)$ & $17(6.8)$ & & & \\
\hline No data & I $(0.2)$ & I $(0.4)$ & - & & & \\
\hline \multicolumn{7}{|l|}{ Education } \\
\hline Low & $102(20.0)$ & $76(29.2)$ & $26(10.4)$ & $<.001^{\mathrm{b}}$ & 28.339 & 2 \\
\hline $\begin{array}{l}\text { Middle } \\
\text { (university- } \\
\text { entrance } \\
\text { diploma) }\end{array}$ & $260(50.9)$ & $116(44.6)$ & I 44 (57.4) & & & \\
\hline $\begin{array}{l}\text { High } \\
\text { (university } \\
\text { degree) }\end{array}$ & I 44 (28.2) & $66(25.4)$ & $78(3 \mid .1)$ & & & \\
\hline No data & $5(1.0)$ & $2(0.8)$ & $3(1.2)$ & & & \\
\hline
\end{tabular}


Table I. Continued

\begin{tabular}{|c|c|c|c|c|c|c|}
\hline & $\begin{array}{l}\text { Total sample } \\
N=5 \text { I I n (\%) }\end{array}$ & $\begin{array}{l}\text { Polish } \\
\text { immigrants } \\
N=260 n(\%)\end{array}$ & $\begin{array}{l}\text { Indigenous } \\
\text { Poles } \\
N=25 \text { I n (\%) }\end{array}$ & $\mathrm{P}$-value & $\begin{array}{l}t \text {-test/ } \\
\chi^{2} \text {-test } \\
\text { values }\end{array}$ & $d f$ \\
\hline \multicolumn{7}{|l|}{$\begin{array}{l}\text { Employment } \\
\text { status }\end{array}$} \\
\hline Employed & $286(56.0)$ & I 48 (56.9) & $138(55.0)$ & $n s^{b}$ & 0.294 & I \\
\hline $\begin{array}{l}\text { Unemployed } 2 \\
\text { (housewife/ } \\
\text { jobless/ } \\
\text { pensioner/ } \\
\text { student) }\end{array}$ & $223(43.6)$ & $110(42.3)$ & II $3(45.0)$ & & & \\
\hline No data & $2(0.4)$ & $2(0.8)$ & - & & & \\
\hline \multicolumn{7}{|l|}{$\begin{array}{l}\text { Subjectively } \\
\text { perceived } \\
\text { income }\end{array}$} \\
\hline $\begin{array}{l}\text { No incomel } \\
\text { very low/low }\end{array}$ & $216(42.3)$ & II 8 (45.4) & $98(39.0)$ & $n s^{b}$ & 2.452 & 2 \\
\hline Middle & $273(53.4)$ & $132(50.8)$ & $|4|(56.2)$ & & & \\
\hline High/very high & $21(4.1)$ & $9(3.5)$ & $12(4.8)$ & & & \\
\hline No data & I $(0.2)$ & I (0.4) & - & & & \\
\hline \multicolumn{7}{|l|}{$\begin{array}{l}\text { Duration of } \\
\text { residence } \\
\text { in Germany }\end{array}$} \\
\hline Mean (in years) & - & 17.98 & - & - & - & - \\
\hline$S D^{*}$ & - & 7.66 & - & & & \\
\hline Range & & $<\mathrm{I}-53$ & & & & \\
\hline \multicolumn{7}{|l|}{$\begin{array}{l}\text { Reasons for } \\
\text { immigration } \\
\text { to Germany }\end{array}$} \\
\hline Family reunion & - & 57 (21.9) & - & - & - & - \\
\hline Economic & - & 57 (21.9) & - & & & \\
\hline $\begin{array}{r}\text { Political and } \\
\text { economic }\end{array}$ & - & $4 \mid(15.8)$ & - & & & \\
\hline Marriage & - & $25(9.6)$ & - & & & \\
\hline Work & - & $18(6.9)$ & - & & & \\
\hline $\begin{array}{l}\text { Children of } \\
\text { immigrants } \\
\text { (birth in } \\
\text { Germany) }\end{array}$ & - & $5(1.9)$ & - & & & \\
\hline Other reasons & - & $4 \mid(15.8)$ & - & & & \\
\hline No data & - & II (4.2) & - & & & \\
\hline
\end{tabular}

Note. $* S D$ standard deviation; $n s$ nonsignificant; ${ }^{a} t$-test; ${ }^{b} \chi^{2}$-test; $d f$ degrees of freedom. 


\section{Measures}

Health-related quality of life. HRQoL was assessed by a generic health status measure, the Short Form Health Survey (SF-36), a widely applied, valid, and reliable instrument consisting of 36 items (Gandek et al., 1998). The SF-36 measures eight dimensions: four dimensions are related to physical health and are summarized as the Physical Component Summary Scale (PCS); four are associated with mental health and are summarized as the Mental Component Summary Scale (MCS). Total scores of the eight subscales of the SF-36 vary from 0 (worst health) to 100 (optimal health). In this study, a validated Polish version of the SF-36 (Marcinowicz \& Sienkiewicz, 2003) produced in the International Quality of Life Assessment Project was applied (with the consent of Health Assessment Lab, Inc.).

\section{Sense of coherence}

The Sense of Coherence Scale $\backslash$ (SOC-29) is a self-report questionnaire consisting of 29 items designed to assess the extent of coherence (Antonovsky, 1987). According to Antonovsky (1987) this represents a basic human orientation consisting of three components: comprehensibility, manageability, and meaningfulness, a higher score indicating a higher SoC. A normative value for the German population on the SOC-29, has been reported as $M=5.34$ (Cronbach's alpha $=.91$; Hannöver et al., 2004). In the present study, an adapted Polish version of the SOC-29 was applied that has proven to have high internal consistency with Cronbach's alpha coefficients ranging from .81 to .91 for the global scale and the subscales (Dudek \& Makowska, 1993).

\section{Data analysis}

All data were analyzed using SPSS Version 17.0. Descriptive statistics, $t$-tests for a sample and independent samples, analyses of variance (ANOVA and ANCOVA), nonparametric tests (Chi-square test, Fisher's exact test, Mann-Whitney U-Test), correlations according to Pearson and Spearman as well as linear regression analyses were carried out. A level of significance of $p<.05$ (two-tailed) was predetermined.

\section{Results}

\section{Health-related quality of life}

Figure 1 presents mean scores of the Physical Component Summary Scale (PCS) for Polish immigrants and native Poles, as well as the norm values of the German population. Figure 2 demonstrates mean scores of Mental Component Summary Scale (MCS) for the three groups. 


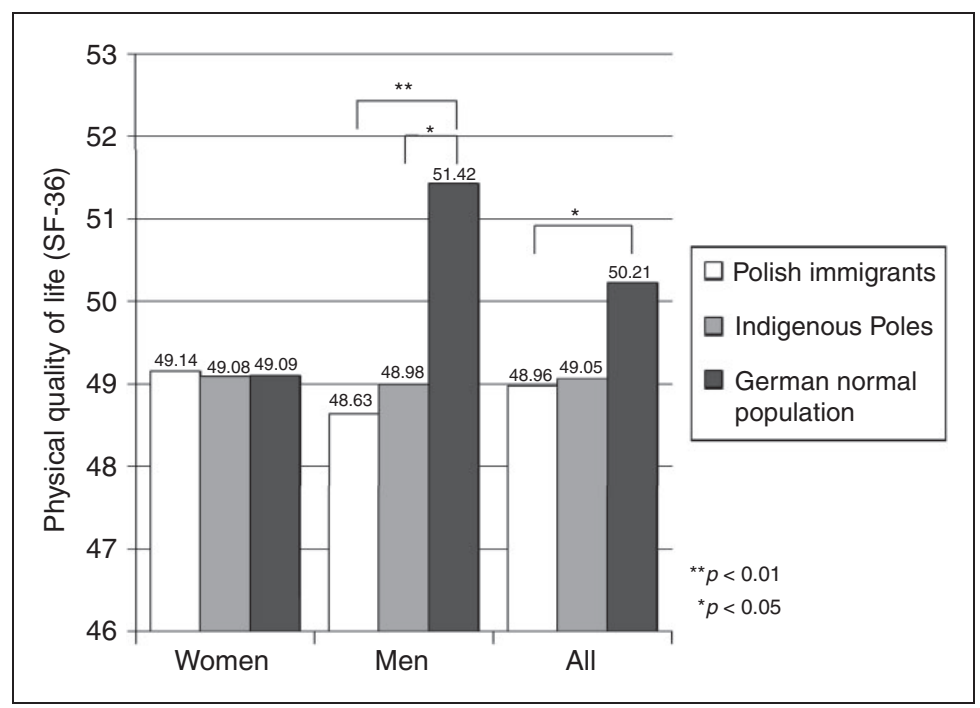

Figure I. Comparison of mean scores on the Physical Component Summary Scale of SF-36 for Polish immigrants, native Poles, and German normal population.

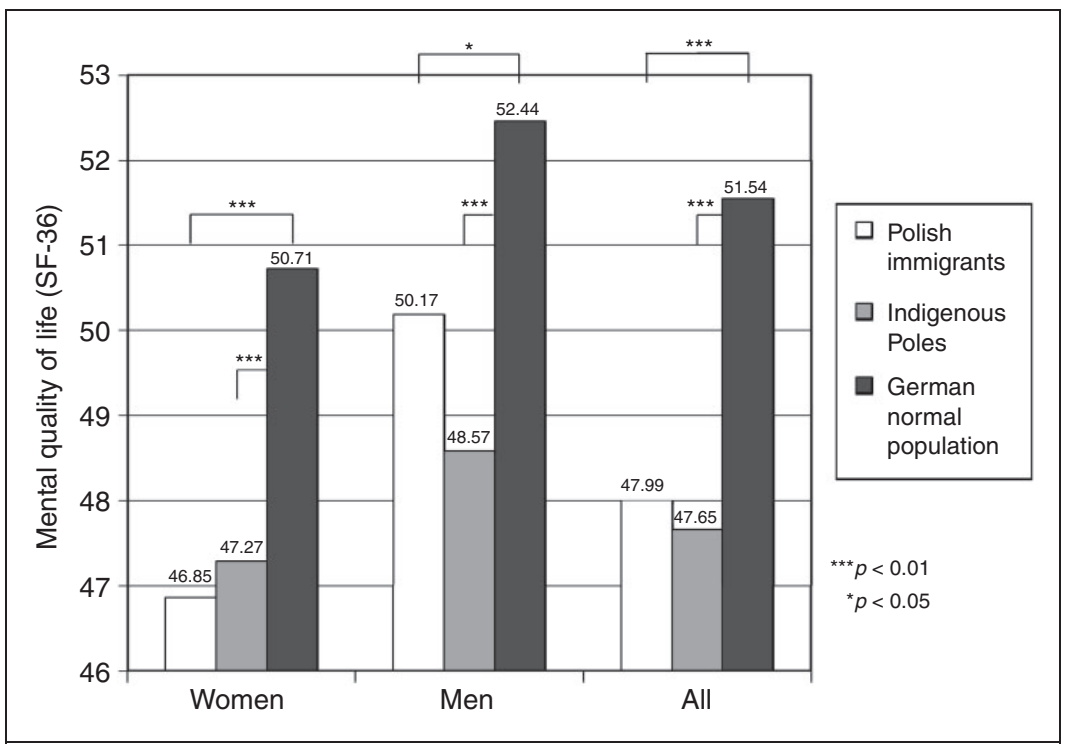

Figure 2. Comparison of mean scores on the Mental Component Summary Scale of SF-36 for Polish immigrants, native Poles, and German normal population. 
In both the PCS and MCS, the immigrant group did not differ significantly from the sample in Poland. In contrast, the Polish immigrants scored significantly lower on both summary scales (PCS: $p=.028$; MCS: $p<.001$ ) in relation to the German norm population. Compared to the German norm population, the indigenous sample reported a significantly lower MCS $(p<.001)$, yet a similar PCS $(p=.062)$.

No gender differences could be demonstrated for the indigenous Polish sample for PCS and MCS. In the group of immigrants, males had a significantly higher MCS mean score $(p=.012)$ than females.

The multivariate analysis of variance of mental health with the factors gender and group affiliation and the covariate age showed a significant influence of the factor gender, $F(1)=6.144, p=.014$ on MCS: Men reported less mental problems and symptoms than women. The multivariate analysis of variance of physical health with the factors gender and group affiliation and the covariate age showed a significant influence of the factor group affiliation, $F(1)=7.303$, $p=.007$ and of the covariate age $F(1)=187.782, p<.001$ on PCS: adjusted for age, Polish immigrants demonstrated a better physical health status than the indigenous Poles.

\section{Sense of coherence}

The mean total score for SoC was $140.64(S D=23.59)$ among Polish immigrants and $138.49(S D=23.44)$ among indigenous Poles (Table 2). Compared to the German norm population $(M=155.0, S D=23.0)$ both samples scored significantly lower on SoC $(p<.001)$, yet did not differ from each other in any significant way $(p=.304)$.

No significant gender differences were found in both examined groups. In all three age classes, the immigrant males and females demonstrated no significant differences compared to the Polish men and women. However, in relation to the German population, both groups scored significantly lower on SoC in every age category except for Polish men aged 41 to 60; these did not differ significantly from the Germans of the same age $(p=.461)$.

No significant gender differences for the age groups could be demonstrated, neither in immigrants nor in the indigenous Poles. Between the age classes, the only significant difference has been observed in the group of the Polish men, $F(2)=6.486, p=.003$ : Men between 41 and 60 years reached a significant higher SoC score than men up to 40 years $(p=.003)$.

\section{Correlation between sense of coherence and other measures}

Significant positive correlations were found between SoC total scores and both summary scales for Polish immigrants as well as for native Poles: The higher the SoC level the better the subjectively perceived health. For both groups, the correlation between SoC and MCS demonstrated high correlation coefficients (immigrants: $r=.606, p<.001$; Poles: $r=.592, p<.001)$, whereas the correlation 


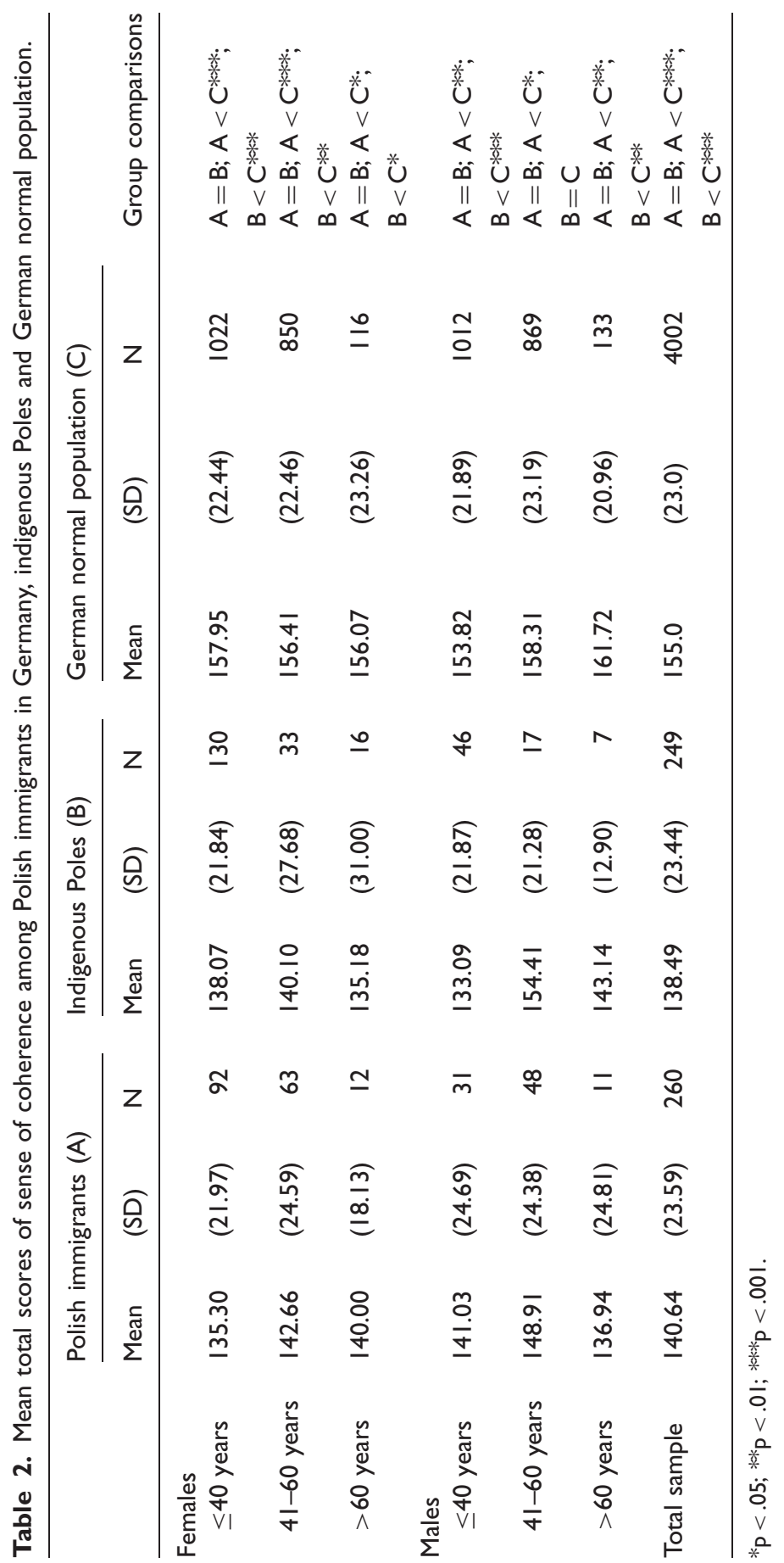


between SoC and PCS was moderate (immigrants: $r=.279, p<.001$; Poles: $r=.149, p=.019)$. In both samples, age did not correlate significantly to SOC, but the subjectively perceived income did (immigrants: $r=.232, p<.001$; Poles: $r=.194, p=.002)$ : the higher the income, the higher the SoC. In the immigrant sample, educational status also correlated significantly to $\operatorname{SoC}(r=.137, p=.028)$ : the higher the educational level, the higher the SoC score. The correlation between SoC and duration of residence in Germany was not significant for the Polish immigrants.

\section{Predictors of health-related quality of life}

To examine the influence of SoC as well as sociodemographic, socioeconomic, and immigration-related variables on HRQoL, step-wise multiple regression analyses were calculated (Table 3). Variables were included in the model when $p<.05$ and removed when $p>.10$.

In Model 1 (physical health in Polish immigrants) and Model 2 (physical health in indigenous Poles), sociodemographic variables such as age, gender, education, employment status (dichotomized), duration of residence in Germany (only in immigrants) and SoC as predictors and Physical Component Summary Scale (PCS) as criterion variable were included. In the immigrant sample, significant predictors were age, SoC, income, and education; for the indigenous Poles significant predictors were age, SoC, and employment status. The explanation of variance of the total score PCS was 27.1\% in Model 1 and $43.9 \%$ in Model 2.

In Model 3 (mental health in Polish immigrants) and Model 4 (mental health in indigenous Poles), SoC proved to be the only significant predictor. The explanation of variance was $38.3 \%$ for the third regression model and $34.5 \%$ for the fourth model.

The results of the regression analyses demonstrate the strong significant influence of SoC for HRQoL; with an increase in SoC, the total physical and mental health score increased. The influence of SoC is apparent especially for mental health, where SoC has been documented to be the only significant predictor.

\section{Discussion}

To the best of our knowledge, the present study is the first to assess generic HRQoL and SoC levels in Polish immigrants in Germany and native Poles. We also investigated the association between HRQoL and SoC and the function of SoC as a protective factor.

The response rate in Germany $(56.3 \%)$ is comparable to studies examining Polish immigrants in Germany, for example, Merbach et al. (2008) report a response rate of $47.5 \%$, whereas the high response rate in Poland $(82.5 \%)$ attracts attention. This could perhaps be explained by the fact that in Poland a relative large group of students had been recruited (larger than in Germany). The recruitment of students was easier than that of nonstudents but resulted in differences 


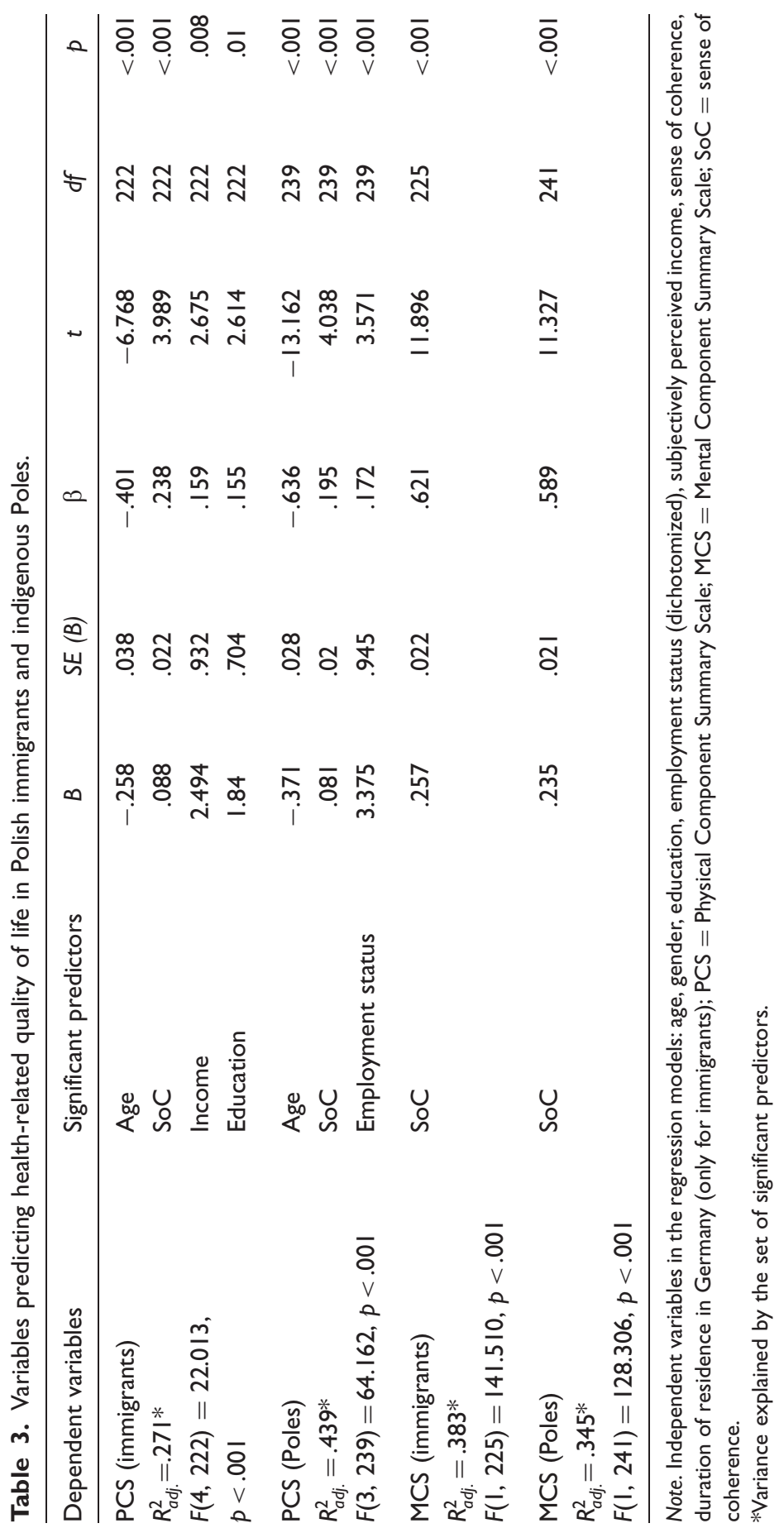


between both samples in some demographic variables: a significantly lower mean age, a significantly greater rate of singles, and a significantly greater rate of persons with a high school education which could have biased the association between the variables group and self-reported health. However, to control the effect of the age, analyses of covariance were carried out.

One main result of our study was a significantly worse self-reported mental as well as physical HRQoL found in the Polish immigrants as compared to the German norm population, a result consistent with previous studies on HRQoL demonstrating better outcome for the indigenous population compared to both Polish immigrants (Silveira et al., 2002) as well as other immigrant groups (Koochek, Montazeri, Johansson, \& Sundquist, 2007). A lower mental as well as physical HRQoL in Polish immigrants in relation to the German norm population may in part be explained depending on different immigration stress theories: Immigration may be associated with various stressors and losses and may be regarded to be a critical life event or even a trauma (Grinberg \& Grinberg, 1990) evoking mental illness or a tendency to somatize (Masumbuku, 1995). Another explanation for a lower HRQoL may be the "goal-striving stress" theory postulating high psychological distress based on the discrepancy between aspirations and achievements (Parker \& Kleiner, 1966). Despite a high educational level $(25.4 \%$ have a university degree), a large percentage $(45.4 \%$ being in a low-income class) of the Polish immigrants demonstrate a low socioeconomic status determined by the subjectively estimated income. Their immigration was in part economically motivated and yet did not lead to an improvement of their financial situation and living conditions, their low economic status could therefore be considered to be a risk factor for poor health and thus correspond to the definition of immigration-specific stressors (Lindström et al., 2001; Wiking et al., 2004).

Both Polish immigrants and indigenous Poles demonstrated a significantly worse self-reported mental health status (MCS) compared to the German norm population; however, they do not differ significantly from each other, a finding that may be explained by the migration import hypothesis (Sungurova, Johansson, \& Sundquist, 2006) in which it is assumed that immigrants' health is related more to the health of the population of their native than to that of their host country. Another explanation may be the East-West health discrepancy, inhabitants of Western Europe demonstrating better health than those from Eastern Europe; an explanation for this discrepancy may be the degree of economic satisfaction (i.e., strongest predictor of self-perceived health), of the control of life, and of participation in civic activities (Carlson, 1998). It may therefore be assumed that as a culture-specific effect Polish culture (that is, sharing the same language, history, traditions, values, and religious beliefs) or being of Polish origin may be a risk factor for poor mental health in this context. This assumption corresponds to the results of a representative study conducted in various European countries assessing the subjective health status with the EuroQoL Five Dimensions Questionnaire (EQ-5D): The local Polish population reported problems related to anxiety/ 
depression almost 10 times more frequently than the German population (38\% vs. 4\%; Golicki, Niewada, Jakubczyk, Wrona, \& Hermanowski, 2010).

The higher mental morbidity of persons of Polish origin may be associated with the history of major social stressors in Poland as experienced by the respondents themselves or by their parents, for example, World War II, followed by a communist regime for over four decades, as well as the radical political and economical transformations in the last 20 years. These multiple, long-persisting stressors may have caused an increased vulnerability in individuals with a Polish cultural background still persisting after immigration. An investigation of 33 Polish immigrants in Great Britain (Keith, 1995) has provided evidence for the persistence of World War II experiences, and subsequent immigration, on health that often lingered into old age. Polish immigrants over 65 years reported poorer health and less life satisfaction and were more troubled by worries compared to the indigenous aged. Decades of a totalitarian system in Poland as well as the transition to democracy and market economy were characterized by difficult political and economic circumstances. People's economic satisfaction and life control as well as participation in civic activities had been substantially reduced for a long time - three important factors having a positive effect on health according to results from a study based on data from national surveys conducted in 25 European countries on self-perceived health ( $n=17.557$; Carlson, 1998).

After adjustment for age, the similarity of both groups concerning the mental HRQoL remained unchanged, however, not for the physical HRQoL; here the immigrants demonstrated a better health status compared to the native Poles. Perhaps the immigrants benefit from the better health care system in Germany, it could, however, also be due to selection processes by immigration ("healthy migrant effect"). To clarify these causal mechanisms, further prospective studies are indicated.

A gender difference in male and female Polish immigrants in mental HRQoL has also been observed; men reporting less mental symptoms than women. This result is in accordance with previous studies on mental health of Polish immigrants (e.g., Silveira et al., 2002) as well as immigrants from other countries (e.g., Levecque, Lodewyckx, \& Bracke, 2009; Tinghög, Al-Saffar, Carstensen, \& Nordenfelt, 2010). Due to the fact that mental HRQoL is a multifaceted phenomenon, a wide range of possible factors has to be considered to explain the worse subjective mental HRQoL in women with a migration background compared to their male counterparts. One reason for this finding may concern the non-immigrant-specific aspect, for example, gender as a risk factor for increased rates of mental disorders and comorbidity (except for substance abuse; Jacobi et al., 2004). Here especially a combination of biological and social perspectives is proposed as an explanation model for the differences in men's and women's health status (cf. Bird \& Rieker, 1999). Other determinants that may have disadvantageously influenced the mental HRQoL of the female immigrants may be differences in the socioeconomic as well as occupational status and further immigration-specific factors like acculturation difficulties or discrimination (cf. Tinghög et al., 2010). 
In mental HRQoL both genders and samples had significantly lower mean values in comparison to the German norm population. In terms of the physical HRQoL, however, only the men scored significantly lower than the German men, whereas both female samples were comparable to the German reference group. The greater differences between men than women in self-reported physical HRQoL in relation to the Germans may be influenced by unhealthy behavioral patterns observed more frequently in men of Polish origin than in women, for example, alcohol consumption, heavy smoking, or BMI (body mass index) $>25 \mathrm{~kg} / \mathrm{m}^{2}$. Alcohol consumption among native Polish men is more than 4 times higher than among women (Sierosławski \& Moskalewicz, 1993), the rate of nonsmokers in Polish male immigrants is $62.1 \%$ versus $72.9 \%$ among female immigrants and the mean BMI is $26.4 \mathrm{~kg} / \mathrm{m}^{2}$ and $24.6 \mathrm{~kg} / \mathrm{m}^{2}$ respectively (Statistisches Bundesamt, 2011b). The culture-specific effect can therefore only be assumed for the mental and not for the somatic dimension of health.

SoC levels were significantly lower in both examined samples compared to the German norm population. One possible explanation for lower SoC scores in persons with a Polish cultural background could be the aforementioned difficult living conditions in Poland; these persons were not able to establish a high SoC, the difficult conditions making it impossible to experience consistent control of life situation, which according to Antonovsky (1987) is essential for the development of a high SoC. One further reason for the low SoC in both Polish groups could be their poor socioeconomic situation: A positive relation between the level of income and the SoC level has previously been reported (Larsson \& Kallenberg, 1996). The disadvantageous socioeconomic factors in our samples could, for example, negatively influence successful manageability of life thus lowering the SoC. Finally, the low SoC could also be interpreted as a culture-specific effect in that persons of Polish origin score lower on SoC because the skills measured in the SoC questionnaire do not correspond to those required in a more collectivistic culture. This assumption is supported by results from a study on patients with mental problems from a collectivistic culture demonstrating significantly lower SoC levels in Turkish patients in Germany and native Turkish patients compared to German controls (Erim et al., 2011). According to Oyserman, Coon, and Kemmelmeier (2002), Western societies represent individualistic societies, whereas Eastern cultures are characterized by collectivism. Poland and other formerly socialist nations of Eastern Europe reflect an intermediate position: a balance of individualistic and collectivistic values (Boski, 2006). On the one hand, Poland has been situated between West and East from a geographical as well as historical point of view, perceiving itself as a Western nation. On the other hand, Poland is one of the most Catholic countries in the world and therefore influenced by the Catholic Church towards more collectivistic than individualistic values. Furthermore, over four decades of forced Soviet collectivism during the communist era in Poland have also influenced the collectivistic orientation of the Polish people (Boski, 2006). Previous studies have shown that high SoC predicts positive health outcomes (Eriksson \& Lindström, 2006, 2007). Correspondingly, we were able to show a positive 
correlation between SoC and both dimensions of HRQoL; correlations between SoC and the mental dimension of HRQoL were even stronger. A possible mechanism underlying the association between $\mathrm{SoC}$ and variables of (mental) health may be the stress-buffering effect of a strong SoC; individuals with a strong SoC might perceive stressful events as more benign and thus feel less stressed by them; they also might cope adequately with stressors using active and nonavoidant strategies (Amirkhan \& Greaves, 2003). A high level of SoC has been shown to moderate the impact of recent stressful life events on self-reported health (Richardson \& Ratner, 2005) and to be associated with fewer reports of stressful events and the application of coping strategies (Kenne Sarenmalm, Browall, Persson, FallDickson, \& Gaston-Johansson, 2013).

\section{Limitations}

The cross-sectional design of the study does not allow causal conclusions of the measured variables to be made. Further prospective investigations are required to explore the effects of culture and immigration on HRQoL and SoC of individuals from different cultures. Another limitation is the selected sample; generalizations involving immigrants in general as well as solely Polish immigrants in particular cannot be carried out; furthermore, a parallelized sample concerning age and gender would be advantageous. The high nonresponse rate in Germany could affect the results through self-selection bias insofar as mental health problems are more common among nonrespondents (cf. Tinghög et al., 2010). The selfreported health of the Polish immigrants observed in the study could therefore reflect an underestimation of the actual mental health status of this immigrant group in Germany. Finally, the significant differences between the immigrants and the native Polish people concerning the demographic variables age, marital status, and education could also have influenced the results. However, in terms of other important (socio-) demographic variables (gender, employment status, and income) both samples were comparable.

One strength of the study is the inclusion of Polish immigrants with limited knowledge of German. Language problems are often an exclusion criterion in epidemiological studies, yet this group is distinctly affected by migration-specific difficulties. An added strength of the study is the inclusion of the control sample in Poland allowing examination of the association between culture and health status.

\section{Conclusion}

We found only minor differences between the Polish immigrants and indigenous Poles on HRQoL. Compared to the general German population HRQoL values for both groups were significantly lower. This suggests the lower HRQoL may reflect the impact of culture more than migration. With respect to SoC the same pattern was found. The high predictive value of SoC on HRQoL suggests that SoC may be a protective factor in persons of Polish origin. 


\section{Conflict of interest}

None declared.

\section{Funding}

This research received no specific grant from any funding agency in the public, commercial, or not-for-profit sectors.

\section{References}

Amirkhan, J. H., \& Greaves, H. (2003). Sense of coherence and stress: The mechanics of a healthy disposition. Psychology and Health, 18, 31-62.

Antonovsky, A. (1987). Unraveling the mystery of health. How people manage stress and stay well. San Francisco, CA: Jossey-Bass.

Bermejo, I., Mayninger, E., Kriston, L., \& Härter, M. (2010). Psychische Störungen bei Menschen mit Migrationshintergrund im Vergleich zur deutschen Allgemeinbevölkerung [Mental disorders in people with migration background compared with German general population]. Psychiatrische Praxis, 37, 225-232.

Bird, C. E., \& Rieker, P. P. (1999). Gender matters: An integrated model for understanding men's and women's health. Social Science and Medicine, 48, 745-755.

Bischoff, A., \& Wanner, P. (2008). The self-reported health of immigrant groups in Switzerland. Journal of Immigrant and Minority Health, 10, 325-335.

Boski, P. (2006). Humanism-materialism: Centuries-long Polish cultural origins and 20 years of research in cultural psychology. In U. Kim, K.-S. Yang, \& K.-K. Hwang (Eds.) Indigenous and cultural psychology: Understanding people in context (pp. 372-403). New York, NY: Plenum Press.

Botschaft der Republik Polen in Berlin [Embassy of the Republic of Poland in Berlin] (n. d.). Die Polen im Ausland - Polonia [The Poles abroad - Polonia]. Retrieved from http:// berlin.msz.gov.pl/de/bilaterale_zusammenarbeit/auslandspolen_127/

Bullinger, M. (1994). Lebensqualität - ein neues Bewertungskriterium für den Therapieerfolg [Quality of life - A new evaluation criterion for the effectiveness of therapy]. In E. Pöppel, M. Bullinger, \& U. Härtel (Eds), Kurzlehrbuch der Medizinischen Psychologie [A short textbook of medical psychology] (pp. 369-376). Weinheim, Germany: VCH Edition Medizin.

Carlson, P. (1998). Self-perceived health in East and West Europe: Another European health divide. Social Science and Medicine, 46, 1355-1366.

Dietz, B. (2008). Aussiedler/Spätaussiedler in Deutschland seit 1950 [Resettlers/late repatriates in Germany since 1950]. In K. J. Bade, P. C. Emmer, L. Lucassen, \& J. Oltmer (Eds), Enzyklopädie Migration in Europa [Encyclopedia Migration in Europe] (pp. 397 404). Paderborn, Germany: Schöningh.

Dudek, B., \& Makowska, Z. (1993). Psychometric characteristics of the Orientation to Life Questionnaire measuring sense of coherence. Polish Psychological Bulletin, 24, 309-318.

Eriksson, M., \& Lindström, B. (2006). Antonovsky's Sense of Coherence Scale and the relation with health: A systematic review. Journal of Epidemiology and Community Health, 60, 376-381.

Eriksson, M., \& Lindström, B. (2007). Antonovsky's Sense of Coherence Scale and its relation with quality of life: A systematic review. Journal of Epidemiology and Community Health, 61, 938-944. 
Erim, Y., Morawa, E., Atay, H., Aygün, S., Gökalp, P., \& Senf, W. (2011). Sense of coherence and depression in the framework of immigration: Turkish patients in Germany and in Turkey. International Review of Psychiatry, 23, 542-549.

Gandek, B., Ware, J. E. Jr, Aaronson, N. K., Alonso, J., Apolone, G., Bjorner, J.,... Sullivan, M. (1998). Tests of data quality, scaling assumptions, and reliability of the SF-36 in eleven countries: Results from the IQOLA Project. Journal of Clinical Epidemiology, 51, 1149-1158.

Glaesmer, H., Wittig, U., Brähler, E., Martin, A., Mewes, R., \& Rief, W. (2009). Sind Migranten häufiger von psychischen Störungen betroffen? Eine Untersuchung an einer repräsentativen Stichprobe der deutschen Allgemeinbevölkerung [Are migrants more susceptible to mental disorders? A study on a representative sample of the German general population]. Psychiatrische Praxis, 36, 16-22.

Golicki, D., Niewada, M., Jakubczyk, M., Wrona, W., \& Hermanowski, T. (2010). Selfassessed health status in Poland: EQ-5D findings from the Polish valuation study. Polish Archives of Internal Medicine, 120, 276-280.

Grinberg, L., \& Grinberg, R. (1990). Die Migration als Trauma und Krise [Migration as trauma and crisis]. In L. Grinberg, \& R. Grinberg (Eds.) Psychoanalyse der Migration und des Exils [Psychoanalysis of migration and exile] (pp. 9-15). Munich, Germany: Verlag Internationale Psychoanalyse.

Hannöver, W., Michael, A., Meyer, C., Rumpf, H. J., Hapke, U., \& John, U. (2004). Die Sense of Coherence Scale von Antonovsky und das Vorliegen einer psychiatrischen Diagnose [Antonovsky's Sense of Coherence Scale and presentation of a psychiatric diagnosis]. Psychotherapie, Psychosomatik, medizinische Psychologie, 54, 179-186.

Info-Dienst Deutsche Aussiedler [Info-Service German emigrants]. (2003). Zahlen, Daten, Fakten [Facts and figures] (Issue 116). Berlin, Germany: Bundesministerium des Innern.

Jacobi, F., Wittchen, H.-U., Hölting, C., Höfler, M., Pfister, H., Müller, N., ...Lieb, R. (2004). Prevalence, co-morbidity and correlates of mental disorders in the general population: Results from the German Health Interview and Examination Survey (GHS). Psychological Medicine, 34, 597-611.

Keith, P. M. (1995). A comparison of the resources and concerns of the Polish and indigenous aged in Britain. Journal of Cross-Cultural Gerontology, 10, 219-231.

Kenne Sarenmalm, E., Browall, M., Persson, L. O., Fall-Dickson, J., \& GastonJohansson, F. (2013). Relationship of sense of coherence to stressful events, coping strategies, health status, and quality of life in women with breast cancer. Psychooncology, 22, 20-27.

Kirkcaldy, B., Wittig, U., Furnham, A., Merbach, M., \& Siefen, R. G. (2006). Migration und Gesundheit. Psychosoziale Determinanten [Migration and health. Psychosocial determinants]. Bundesgesundheitsbl Gesundheitsforsch Gesundheitsschutz, 49, 873-883.

Koochek, A., Montazeri, A., Johansson, S.-E., \& Sundquist, J. (2007). Health-related quality of life and migration: A cross-sectional study on elderly Iranians in Sweden. Health and Quality of Life Outcomes, 5, 1-8.

Larsson, G., \& Kallenberg, K. O. (1996). Sense of coherence, socioeconomic conditions and health. Interrelationships in a nation-wide Swedish sample. European Journal of Public Health, 6, 175-180. 
Levecque, K., Lodewyckx, I., \& Bracke, P. (2009). Psychological distress, depression and generalized anxiety in Turkish and Moroccan immigrants in Belgium. A general population study. Social Psychiatry and Psychiatric Epidemiology, 44, 188-197.

Lindström, B., \& Eriksson, M. (2005). Salutogenesis. Journal of Epidemiology and Community Health, 59, 440-442.

Lindström, M., Sundquist, J., \& Östergren, P.-O. (2001). Ethnic differences in self reported health in Malmö in southern Sweden. Journal of Epidemiology and Community Health, $55,97-103$.

Marcinowicz, L., \& Sienkiewicz, J. (2003). Badanie trafności i rzetelności polskiej wersji kwestionariusza SF-36: wyniki wstępne [The assessment of validity and reliability of the Polish version of the SF-36: Preliminary findings]. Przegl Lek, 60 (Suppl. 6): 103-106.

Masumbuku, J. R. (1995). Psychische Schwierigkeiten von Zuwanderern aus den ehemaligen Ostblockländern [Mental problems of immigrants from the former Eastern bloc countries]. Weinheim, Germany: Deutscher Studien Verlag.

Morawa, E. (2009). Patrioten, Überlebenskünstler, Chaoten? - Eine Einführung in die Spezifik der polnischen Identität und Kultur [Patriots, survivalists, anarchists? - An introduction to the specifics of the Polish identity and culture]. In Y. Erim (Ed.), Klinische Interkulturelle Psychotherapie: ein Lehr- und Praxisbuch [Clinical Intercultural psychotherapy: A text and practice book] (pp. 263-277). Stuttgart, Germany: Kohlhammer.

Oyserman, D., Coon, H. M., \& Kemmelmeier, M. (2002). Rethinking individualism and collectivism: Evaluation of theoretical assumptions and meta-analyses. Psychological Bulletin, 128, 3-72.

Pallaske, C. (2002). Migrationen aus Polen in die Bundesrepublik Deutschland in den 1980er und 1990er Jahren: Migrationsverläufe und Eingliederungsprozesse in sozialgeschichtlicher Perspektive [Migrations from Poland to the Federal Republic of Germany in the 1980s and 1990s: Migration patterns and integration processes in socio-historical perspective]. Münster, Germany: Waxmann.

Parker, S., \& Kleiner, R. (1966). Mental illness in the urban Negro community. New York, NY: Free Press.

Richardson, C. G., \& Ratner, P. A. (2005). Sense of coherence as a moderator of the effects of stressful life events on health. Journal of Epidemiology and Community Health, 59, 979-984.

Schenk, L., Bau, A. M., Borde, T., Butler, J., Lampert, T., Neuhauser, H.,... Weilandt, C. (2006). Mindestindikatorensatz zur Erfassung des Migrationsstatus. Empfehlungen für die epidemiologische Praxis [A basic set of indicators for mapping migrant status. Recommendations for epidemiological practice]. Bundesgesundheitsbl Gesundheitsforsch Gesundheitsschutz, 49, 853-860.

Sierosławski, J., \& Moskalewicz, J. (1993). Spożycie alkoholu w Polsce w $1993 r$ [Alcohol consumption in Poland in 1993]. Warsaw, Poland: Państwowa Agencja Rozwiązywania Problemów Alkoholowych [The States Agency for Prevention of Alcohol Related Problems].

Silveira, E., Skoog, I., Sundh, V., Allebeck, P., \& Stehen, B. (2002). Health and well-being among 70-year-old migrants living in Sweden - Results from the $\mathrm{H} 70$ gerontological and geriatric population studies in Göteborg. Social Psychiatry and Psychiatric Epidemiology, 37, 13-22. 
Statistisches Bundesamt [Federal Statistical Office]. (2011a). Bevölkerung und Erwerbstätigkeit. Bevölkerung mit Migrationshintergrund. Ergebnisse des Mikrozensus 2010 [Population and employment. Population with an immigrant background. Results of the Microcensus 2010]. Retrieved from https://www.destatis.de/DE/Publikationen/ Thematisch/Bevoelkerung/MigrationIntegration/Migrationshintergrund2010220107004 .pdf?_blob=publicationFile

Statistisches Bundesamt [Federal Statistical Office]. (2011b). Bevölkerung und Erwerbstätigkeit. Bevölkerung mit Migrationshintergrund. Ergebnisse des Mikrozensus 2009 [Population and employment. Population with an immigrant background. Results of the Microcensus 2009]. Retrieved from https://www.destatis.de/DE/Publikationen/ Thematisch/Bevoelkerung/MigrationIntegration/Migrationshintergrund2010220097004. pdf?_blob=publicationFile

Sungurova, Y., Johansson, S.-E., \& Sundquist, J. (2006). East-West health divide and EastWest migration: Self-reported health of immigrants from Eastern Europe and the former Soviet Union in Sweden. Scandinavian Journal of Public Health, 34, 217-221.

Tinghög, P., Al-Saffar, S., Carstensen, J., \& Nordenfelt, L. (2010). The association of immigrant- and non-immigrant-specific factors with mental ill health among immigrants in Sweden. International Journal of Social Psychiatry, 56, 74-93.

Wiking, E., Johansson, S. E., \& Sundquist, J. (2004). Ethnicity, acculturation, and self reported health. A population based study among immigrants from Poland, Turkey, and Iran in Sweden. Journal of Epidemiology and Community Health, 58, 574-582.

Wittig, U., Lindert, J., Merbach, M., \& Brähler, E. (2008). Mental health of patients from different cultures in Germany. European Psychiatry, 23, 28-35.

Zych, A. A., \& Bartel, R. (1988). Zur Lebenssituation alternder Menschen in Polen und in der Bundesrepublik Deutschland - eine komparative Survey-Studie [Life situation of aging people in Poland and the Federal Republic of Germany - A comparative survey study]. Giessen, Germany: Institut für Heil- und Sonderpädagogik, Justus-Liebig-Universität.

Eva Morawa, Dr. rer. medic., Dipl.-Psych., Dipl.-Theol., is a graduate of psychology and theology and works as a research assistant at the Department of Psychosomatic Medicine and Psychotherapy at the University Hospital of Erlangen. Her doctoral thesis concerned the prevalence of depression and anxiety in immigrants of Polish descent and indigenous Poles. She also conducted research on symptom severity and protective factors for mental disorders among Turkish immigrants and other ethnic populations in Germany.

Yesim Erim, MD, is Head of the Department of Psychosomatic Medicine and Psychotherapy and teaching professor at the University Hospital of Erlangen. Professor Erim was the Principal Investigator on the Cooperative Study for the Optimization of the Psychiatric Outpatient Services for Immigrants in North Rhine-Westphalia, including nine psychiatric hospitals in the region supported by the local administration (Landschaftsverband) from 2006 to 2013. Her published works focus on the prevalence of mental disorders in ethnic groups, culturally adapted psychotherapy, as well as the translation and validation of questionnaires. Another focus of her work is psychotherapeutic interventions with the physically ill. 